\title{
A Needs Analysis for the Development of Forest Healing Programs: Focusing on Cancer Patients
}

\author{
Mi-Mi Lee ${ }^{1}$, Don-Gak Lee ${ }^{1}$, and Bong-Ju Park ${ }^{2 *}$ \\ ${ }^{1}$ Doctoral student, Department of Forest Therapy, Graduate School, Chungbuk National University, Cheongju 28644, Korea \\ ${ }^{2}$ Professor, Department of Horticultural Science, Chungbuk National University, Cheongju 28644, Korea
}

\section{ABSTRACT}

Background and objective: Cancer is the number one cause of death in Korea, and it affects any part of the body regardless of gender and age. Forest healing is a treatment that maximizes the effect of treatment and improves the quality of life. This study aims to provide basic data for the development and implementation of differentiated forest healing programs for cancer patients based on the survey on their interest and needs for the programs.

Methods: The subjects were those diagnosed with cancer from October 2018 to April 2019, and this study used 144 copies of the questionnaire retrieved. The sample size of this study $(n=144)$ was the appropriate size required by G-Power, and the collected responses were analyzed using SPSS 25.0.

Results: In the frequency analysis on the interest in forest healing, $79.2 \%$ of the subjects had no experience participating in forest healing, but $87 \%$ were aware of it, and $82.6 \%$ showed the intention to participate in forest healing programs. This indicates that even though not many of them have experience participating in forest healing, they showed high interest and needs for participation. They preferred to participate in spring (29.9\%) and fall (27.8\%), in programs carried out for 1.5-2 hours in the morning on weekdays.

Conclusion: This study has implications for the analysis on forest healing needs of cancer patients, and it is necessary to plan, develop, and implement differentiated forest healing programs that meet the needs of the cancer patients depending on their characteristics. There is also a need to plan forest healing program that can promote both psychological stability and physical health of cancer patients and verify and evaluate their effects based on specialized training of forest healing instructors.

Keywords: forest therapy program, forest care program, preferences, visitor characteristics

\section{Introduction}

People today show greater interest in promoting health and preventing diseases, and the development of medical technology has led to the longer average lifespan. Nonetheless, stress, cerebrovascular diseases, neurosis, anxiety, depression, suicide, heart diseases, and cancer patients are increasing, and cancer is the number one cause of death in Korea. According to the 2018 statistics of National Cancer Information Center, total 79,153 deaths were caused by cancer, most of which were by lung cancer $(22.5 \%, 17,852$ deaths), followed by liver cancer (13.4\%), colorectal cancer (11.1\%), gastric cancer (9.8\%), and pancreatic cancer (7.6\%). By gender and mortality rates of major cancer types, 48,898 men died from cancer, indicating that $30.3 \%$ of all deaths in men are caused by cancer. Cancer with highest mortality rate in men was lung cancer $(27 \%, 13,188$ deaths), followed by liver cancer (15.9\%), gastric cancer (10.4\%), and colorectal cancer (10.1\%). Total 30,255 women died from cancer, indicating that $22.0 \%$ of all deaths in women are caused by cancer. Cancer with highest mortality rate in women was lung cancer (15.4\%, 4,664 deaths), followed

Received: September 11, 2020, Revised: October 12, 2020, Accepted: November 2, 2020

First author: Mi-Mi Lee, yulim741@naver.com, (1) https://orcid.org/0000-0001-5499-4360

*Corresponding author: Bong-Ju Park, bjpak@chungbuk.ac.kr, (1D) https://orcid.org/0000-0001-5511-4812 
by colorectal cancer (12.8\%), pancreatic cancer $(9.4 \%)$, and liver cancer (9.3\%) (National Cancer Information Center, 2019).

Industrialization and urbanization increased people's interest in recreation as well as desires for stability and recovery of health the mind and the body, which led to growing interest in forests for health and precaution against diseases. Forests began to be perceived as a place for relaxation and healing in the Forestry Culture and Recreation Act amended in March 2010. According to Article 2, paragraph (4) of this Act, forest healing is defined as 'immune-strengthening and health-promoting activities, which utilize a variety of elements of the forest, including scents and scenic views' (Korea Forest Service, 2011). As an intervention for treatment and recovery of cancer patients, there is an increasing need for a customized forest healing program based on target analysis in the planning process using natural ingredients of forests (Hong et al., 2010). Forests and natural materials are known to have a positive impact on emotional, psychological, and physical stability as well as self-realization and to alleviate depression, and thus used to treat, recover, and alleviate diseases such as cancer (Shin et al., 2007). Forest activities may be a physiological and psychological treatment as they reduce stress and increase alpha waves, and also affect the immune function (Park, 2010). In the attention restoration theory, forests help recover health physiologically and psychologically through being away, extent, fascination, compatibility, and comfort (Kaplan, 1995). Forest healing programs for subjects visiting the forest require a needs analysis according to the frequency of forest visits and a preference analysis according to the level of stress (Lee and Kim, 2011). A forest healing program that meets the characteristics and therapeutic goals must be developed depending on the subjects (Kim et al., 2014a). For the analysis of needs and preferences of the subjects, it is necessary to determine the theme, therapy, and accurate subject information (Kim, 2016b), and to develop a differentiated and customized program based on the disease through analysis of activities (Son et al., 2012). To maximize the therapeutic effects, activities must be carried out in forests with abundant physiological conditions (air, water, sunlight, anion, place, exercise, herbs, terpene) and mental conditions (Morita therapy, Zazen, be- havior, music, amusement, kinesitherapy, autogenic training, forest smells, sounds of birds, winds, anion) (Kim, 2006). As such, previous studies had emphasized the need to develop a differentiated and customized program with preference and needs analyses according to the subjects visiting the forest. However, it is difficult to find research cases that analyzed the preference and needs for forest healing programs targeting cancer patients using the healing elements of the forest. Accordingly, this study was conducted to provide basic data for development and implementation of a differentiated forest healing program through surveys and analysis on interests and needs for forest healing with potential cancer patients that will be participating in the forest healing program.

\section{Research Methods}

\section{Subjects and survey method}

To develop the survey items that meet the purpose of this study, we analyzed 18 previous studies and came up with total 60 items: 6 demographic questions to determine the subjects, 9 questions on interest in forest healing. 6 questions on preference in forest healing programs (psychotherapy, kinesiology, climate therapy, plant therapy, water therapy, diet therapy), 25 sub-items, 4 questions on preference in the purpose of participating in a forest healing program (physical/psychological/social/cognitive), and 16 sub-items, with the preference and purpose developed to be rated on a five-point Likert scale (Table 1). To improve completeness of the questionnaire, five related experts (two Forest Therapist-Grade 1, forest education specialist, nurse, Horticultural Therapist Registered for Wellbeing-Grade I) developed and reviewed the questionnaire. Hospitalized cancer patients were excluded from the subjects due to the nature of this study. The subjects were recruited through cancer patients' self-help groups and health centers in some parts of Gyeonggi-do, Gwangju (Jeonnam), Jinju (Gyeongnam), Jeju-do, Yesan and Seosan (Chungnam), and Cheongju (Chungbuk), among those diagnosed with cancer from October 2018 to April 2019. After explaining the intent and purpose of this study, we 
Table 1. Analysis of previous studies

\begin{tabular}{lll}
\hline \multicolumn{1}{c}{ Author } & \multicolumn{1}{c}{ Target } & \multicolumn{1}{c}{ Contents } \\
\hline Kim et al. (2002) & 116 Cancer patients & $\begin{array}{l}\text { Development of tools required for cancer patients } \\
\text { Characteristics of healing elements }\end{array}$ \\
Kim (2006) & Theoretical consideration & Forest recreation activities and programs \\
Lee et al. (2011) & Forest recreation 12 people x 24 area & Program target, content and composition analysis \\
Lee and Kim (2011) & 24 forest healing program & Visitiors' behaviors and needs of recrational forest \\
Son et. al. (2012) & 460 National recreational forest visitiors & Preference of forest road recreation program \\
Baik and Kim (2014) & 110 Cancer patients & Health needs \\
Choi and Ha (2014) & 28 Cancer patients & Forest activity program \\
Kim et al. (2014a) & 613 General adults & Forest and forest road preference \\
Kim et al. (2014b) & 516 General adults & Preference according to demographic characteristics \\
Kim Y.H. et al. (2015a) & 245 General adults & MBTI personality type program preference \\
Kim Y.G. et al. (2015b) & 27 Cancer patients & Forest activity program \\
Yeom et al. (2015) & 22 Program experts & Forest healing program contents \\
Kim (2016a) & 620 Adults in their 20s-60s & Preference according to stress \\
Kim (2016b) & 260 Aadult men and women & Program preference \\
Kim (2016c) & 660 Adults in their 20s-60s & Forest healing program requirements \\
Lee et al. (2016) & 2,169 Healing forest guest & Satisfaction with healing forest program \\
Park and Koo (2018) & 300 Incheon Grand Park & Purpose of participation in forest healing programs \\
\hline
\end{tabular}

retrieved the self-administered survey from those who wanted voluntary participation and gave them serial numbers. Total 162 copies of the questionnaire were retrieved, but we used 144 copies for statistical analysis excluding 18 copies that lack accuracy and statistics.

\section{Methods of data analysis}

The survey responses were analyzed using SPSS 25.0. We used frequency analysis on the demographic characteristics and questions about interest in forest healing, descriptive statistics on preference in forest healing programs and purpose of forest healing to verify the expected outcomes of participation, chi-squared test and Fisher's exact test to verify the differences of interest in forest healing depending on gender and name of the disease, and independent samples t-test and one-way ANOVA on preference in forest healing programs and purpose of the programs to verify the difference in preference.

\section{Results and Discussion}

\section{Demographic characteristics of the subjects}

The demographic characteristics of the subjects were analyzed by gender, age, marital status, occupation, and education. 30.6\% were men (44 subjects) and 69.4\% were women (100 subjects), most of which were in their 50s, and the female participation rate was higher since it was difficult to retrieve the survey from the male participants. $84 \%$ of them were married (121 subjects), and most of them were full-time homemakers $(37.5 \%, 54$ subjects), followed by professional practice, service, teaching/office, and production. Most of them were high school graduates (45.8\%, 66 subjects), followed by middle school graduates, university graduates or higher, and elementary school graduates. $7.7 \%$ of the subjects were under the age of 39 (11 subjects) and 13.2\% were over 70 (19 subjects), and they had a variety of occupations (Table 2).

\section{Clinical characteristics of the subjects}

The subjects received treatment from minimum 1 month 
Table 2. Demographic characteristics of the research subject

\begin{tabular}{|c|c|c|c|}
\hline Variable & Category & $\mathrm{n}$ & Percent $(\%)$ \\
\hline \multirow{2}{*}{ Gender } & Male & 44 & 30.6 \\
\hline & Female & 100 & 69.4 \\
\hline \multirow{5}{*}{ Age } & Under 39 & 11 & 7.6 \\
\hline & $40 \sim 49$ & 23 & 16.0 \\
\hline & $50 \sim 59$ & 55 & 38.2 \\
\hline & $60 \sim 69$ & 36 & 25.0 \\
\hline & Over 70 & 19 & 13.2 \\
\hline \multirow{5}{*}{ Marriage } & Single & 4 & 2.8 \\
\hline & Married & 121 & 84.0 \\
\hline & Divorce & 5 & 3.5 \\
\hline & Separation & 3 & 2.1 \\
\hline & Death and death & 11 & 7.6 \\
\hline \multirow{4}{*}{ Education } & Elementary school & 19 & 13.2 \\
\hline & Middle school & 39 & 27.1 \\
\hline & High school & 66 & 45.8 \\
\hline & University & 20 & 13.9 \\
\hline \multirow{8}{*}{ Occupation } & Teacher & 11 & 7.6 \\
\hline & Production & 5 & 3.5 \\
\hline & Office & 11 & 7.6 \\
\hline & Sever & 13 & 9.0 \\
\hline & $\begin{array}{l}\text { Professional } \\
\text { occupation }\end{array}$ & 25 & 17.4 \\
\hline & Housewife & 54 & 37.5 \\
\hline & Jobless person & 17 & 11.8 \\
\hline & Other & 8 & 5.6 \\
\hline \multicolumn{2}{|c|}{ Total } & 144 & 100.0 \\
\hline
\end{tabular}

to maximum 5 years, for 10 months on average. Most had breast cancer (38.9\%, 56 subjects) -- partly because there were more female subjects in this study -- followed by gastric cancer (38.9\%) and lung cancer (38.9\%), and 4 out of 14 subjects with thyroid cancer $(9.7 \%)$ were men. 59.7\% received chemotherapy, most of them were in Stage 1 (61.8\%), and all subjects except 29 of them had already received surgical treatment at least once (Table 3).

\section{Interest in forest healing}

Multiple-choice questions were used to determine the interest in forest healing among the subjects. 52.1\% (75 subjects) went to a mountain or a forest once a week, $14.6 \%$ (21 subjects) went once a month, $2.1 \%$ (3 subjects) went
Table 3. Clinical characteristics of the study subject

\begin{tabular}{|c|c|c|c|}
\hline \multicolumn{2}{|c|}{ Variable } & $\mathrm{n}$ & Percent $(\%)$ \\
\hline \multirow{8}{*}{ Cancer types } & Thyroid cancer & 14 & 9.7 \\
\hline & Colorectal cancer & 10 & 6.9 \\
\hline & Gastric cancer & 12 & 8.3 \\
\hline & Breast cancer & 56 & 38.9 \\
\hline & Lung cancer & 12 & 8.3 \\
\hline & Liver cancer & 8 & 5.6 \\
\hline & Ovarian cancer & 8 & 5.6 \\
\hline & Various cancer & 24 & 16.7 \\
\hline \multirow{4}{*}{ Unit } & 1 unit & 89 & 61.8 \\
\hline & 2 unit & 30 & 20.8 \\
\hline & 3 unit & 20 & 13.9 \\
\hline & 4 unit & 5 & 3.5 \\
\hline \multirow{4}{*}{ Chemotherapy } & Zero & 58 & 40.3 \\
\hline & One $\sim$ five & 46 & 31.9 \\
\hline & $\mathrm{Six} \sim$ ten & 30 & 20.8 \\
\hline & Eleven & 10 & 6.9 \\
\hline \multirow{3}{*}{ Surgical treatment } & Zero & 29 & 20.1 \\
\hline & One & 94 & 65.3 \\
\hline & Two & 21 & 14.6 \\
\hline \multirow{2}{*}{ Medicine } & Not taking & 58 & 40.3 \\
\hline & Taking & 86 & 59.7 \\
\hline
\end{tabular}

once every 3 months, $6.3 \%$ ( 9 subjects) went once every 6 months, $4.2 \%$ (6 subjects) went once a year, and 18.1\% (26 subjects) almost never went. 87\% (120 subjects) claimed to have heard of forest healing, $36.7 \%$ (44 subjects) on TV, $33.3 \%$ (40 subjects) on the internet, and 17.5\% (21 subjects) on SNS, but 79.2\% (114 subjects) had no experience participating in forest healing. 82.6\% (118 subjects) were willing to participate in a forest healing program, and 9,8\% (14 subjects) were not. In a previous study that surveyed the preference of adults in forest healing programs, men were more aware of forest healing than women, and most of whom experienced the programs were in their 50s, followed by 40s, 30s, and 20s (Kim et al., 2014b). $29.9 \%$ (43 subjects) responded they preferred spring, 6.9\% summer (10 subjects), $27.8 \%$ fall (40 subjects), $0.7 \%$ winter ( 1 subjects), and $34.7 \%$ responded that the season does not matter (50 subjects). In a previous study, the 20 s preferred half a day and a day, and 30s-50s preferred overnight and half a day (Kim et al., 2014b), but in this study, 42.4\% 
(61 subjects) preferred 1 hour and 30 minutes, 40.3\% (58 subjects) preferred 2 hours, and 9.0\% (13 subjects) preferred 3 hours. $4.9 \%$ (7 subjects) said they want to participate once a month, $38.2 \%$ (55 subjects) once a week, $33.3 \%$ (48 subjects) twice a week, 7.6\% (11 subjects) 3 times a week, $3.5 \%$ (5 subjects) 4 times a week, $4.9 \%$ (7 subjects) 5 times a week, and 7.6\% (11 subjects) every day (Table 4). An analysis on the visitor characteristics of healing forests showed that many visitors are satisfied with 2-4 hours of experience-based programs in the spring, but it is necessary to organize different programs depending on the disease (Kim et al., 2016b). Since satisfaction varies depending on whether one has a disease or not, the needs of the subjects must be reflected in order to create a good program (Lee et al., 2016). Thus, it is necessary to plan and develop specialized programs based on analysis of interests and needs of the subjects in forest healing and train forest therapists with professional knowledge in the programs. In this study, cancer patients had a high level of awareness about forest healing but had relatively little experience in actually participating in a forest healing program, and yet they showed a strong will to participate. Thus, there is a need for forest healing programs that are suitable for the characteristics of cancer patients by determining their needs and preferences to alleviate their psy-

Table 4. Forest healing interest

\begin{tabular}{clcc}
\hline Variable & \multicolumn{1}{c}{ Category } & $\mathrm{n}$ & Percent(\%) \\
\hline & Once a week & 75 & 53.6 \\
& Once a month & 21 & 14.6 \\
Mountain, & Once in 3 months & 3 & 2.1 \\
forest visit & Once in 6 months & 9 & 6.3 \\
& Once a year & 6 & 4.2 \\
& None & 26 & 18.1 \\
Forest healing & Yes & 120 & 87.0 \\
awareness & No & 24 & 13.0 \\
& Books & 3 & 2.5 \\
& Newspaper & 6 & 5.0 \\
& Magazine & 2 & 1.7 \\
Forest healing & TV & 44 & 36.7 \\
cognitive path & SNS & 21 & 17.5 \\
& Acquaintance & 40 & 33.3 \\
& Other & 4 & 3.3 \\
\hline
\end{tabular}

Table 4. (continued)

\begin{tabular}{|c|c|c|c|}
\hline Variable & Category & $\mathrm{n}$ & Percent(\%) \\
\hline \multirow{2}{*}{$\begin{array}{c}\text { Forest healing } \\
\text { program experience }\end{array}$} & Yes & 30 & 20.8 \\
\hline & No & 114 & 79.2 \\
\hline \multirow{5}{*}{$\begin{array}{l}\text { Participation in } \\
\text { forest healing } \\
\text { program }\end{array}$} & Yes & 65 & 45.2 \\
\hline & Some intention & 54 & 37.5 \\
\hline & Usually & 11 & 7.6 \\
\hline & Not much & 10 & 6.9 \\
\hline & No & 4 & 2.8 \\
\hline \multirow{5}{*}{$\begin{array}{l}\text { Who wants to } \\
\text { participate } \\
\text { together }\end{array}$} & Spouse/Couple & 88 & 61.1 \\
\hline & Children & 11 & 7.6 \\
\hline & Friend & 24 & 16.7 \\
\hline & Alone & 18 & 12.5 \\
\hline & Other & 3 & 2.1 \\
\hline \multirow{7}{*}{$\begin{array}{c}\text { Day of } \\
\text { participation }\end{array}$} & Weekday morning & 71 & 49.2 \\
\hline & Weekday afternoon & 15 & 10.4 \\
\hline & Saturday morning & 22 & 15.3 \\
\hline & Saturday afternoon & 5 & 3.5 \\
\hline & Sunday morning & 8 & 5.6 \\
\hline & Sunday afternoon & 3 & 2.1 \\
\hline & Does not matter & 20 & 13.9 \\
\hline \multirow{4}{*}{$\begin{array}{l}\text { Engagement } \\
\text { time }\end{array}$} & Dawn & 4 & 2.8 \\
\hline & Morning & 109 & 75.7 \\
\hline & Afternoon & 17 & 11.8 \\
\hline & Does not matter & 14 & 9.7 \\
\hline \multirow{5}{*}{$\begin{array}{l}\text { Participating } \\
\text { season }\end{array}$} & Spring & 43 & 29.9 \\
\hline & Summer & 10 & 6.9 \\
\hline & Fall & 40 & 27.8 \\
\hline & Winter & 1 & 0.7 \\
\hline & Does not matter & 50 & 34.7 \\
\hline \multirow{6}{*}{ Program time } & 1 hour & 7 & 2.7 \\
\hline & 1 hour 30 minutes & 61 & 42.4 \\
\hline & 2 hours & 58 & 40.3 \\
\hline & 2 hour 30 minutes & 7 & 4.9 \\
\hline & 3 hours & 13 & 9.0 \\
\hline & Does not matter & 1 & 0.7 \\
\hline \multirow{7}{*}{ Engagements } & Once a month & 7 & 4.9 \\
\hline & Once a week & 55 & 38.2 \\
\hline & Twice a week & 48 & 33.3 \\
\hline & 3 times a week & 11 & 7.6 \\
\hline & 4 times a week & 5 & 3.5 \\
\hline & 5 times a week & 7 & 4.9 \\
\hline & Everyday & 11 & 7.6 \\
\hline \multicolumn{2}{|c|}{ Total } & 144 & 100.0 \\
\hline
\end{tabular}


chological depression, anxiety, and stress and promote quality of life and physical functions. In addition, it is necessary to develop forest healing programs that meet the needs of the subjects according to the four seasons as well as the purpose and characteristics of the program and implement them in the actual scene based on effectiveness studies.

\section{Difference of interest in forest healing depending on gender and cancer types}

\section{Difference of interest in forest healing depending on gender}

Interest in forest healing (who they want to participate with, number of visits, awareness of forest healing, path of forest healing awareness, intention to participate, desired day of the week, participating time, number of participations, season, gender) showed a significant difference depending on gender. More specifically, most men responded they want to participate with their spouse or lover (81.8\%), whereas only $52 \%$ of women (52 subjects) responded the same, which showed a significant difference; other than that, there was no significant difference in the items of interest in forest healing (Table 5). In the needs for programs using urban forests, the $20 \mathrm{~s}$ and 40 s highly appreciated forest healing factors, while the $30 \mathrm{~s}$ and $50 \mathrm{~s}$ attached greatest importance to forest healing programs, claiming that differentiated programs must be provided depending on the age of participants (Park and Koo, 2018). A previous study stated that by gender, women preferred spring and men preferred fall, and by age, the 20s-30s preferred fall and the 40s-50s preferred spring; and since the sensitivity and emotions of the subjects all vary, the programs cannot be limited to just one season and instead must be differentiated by seasons (Kim et al., 2014b). As such, this study discovered that more women visited the forest than men and also more often, and that the subjects wanted to participate in the programs with their spouses or lovers. Thus, it is necessary to develop a program in which the subjects can participate with their spouses. There was a difficulty in securing the subjects due to the nature of their characteristics, but it seems necessary to conduct a systematic survey on the subjects by cancer types they are diagnosed with.

\section{Difference of interest in forest healing depending on cancer types}

There was a difference of interest in forest healing depending on the name of cancer types. The subjects with colorectal/breast/lung/liver/other types of cancer visited the forest once a week, those with thyroid/ovarian cancer once every 6 months, and those with gastric cancer once a year (Table 6). Those with breast cancer were most aware of forest healing programs, followed by other types of cancer, thyroid cancer, colorectal cancer, gastric cancer, lung/liver cancer, and ovarian cancer (Table 7). 45.1\% (breast cancer, other types of cancer, lung cancer, colorectal/lung cancer, thyroid/gastric cancer, ovarian cancer) showed the intention to participate in the program, but $17.4 \%$ (breast cancer, gastric/lung/other types of cancer, lung cancer) did not (Table 8). For participation, 59.7\% (breast cancer, other types of cancer, lung cancer, thyroid/colorectal cancer, gastric cancer, ovarian cancer, lung cancer) preferred mornings (49.3\%) and afternoons (10.4\%) on weekdays, $18.8 \%$ (breast cancer, thyroid/gastric cancer, colorectal/lung/other types of cancer, ovarian cancer) preferred Saturday mornings (15.3\%) and afternoons (3.5\%), and 7.7\% (breast cancer, thyroid cancer, lung/other types of cancer) preferred Sunday mornings (5.6\%) and afternoons (2.1\%) (Table 9). The subjects with breast cancer, other types of cancer, thyroid cancer, colorectal/gastric cancer, ovarian cancer, and lung/liver cancer wanted to participate in the morning (Table 10). According to previous studies, it is necessary to develop programs that can increase the duration and desire to produce effects through forest activities depending on the characteristics of the subjects (Kim et al., 2015b), develop regular programs considering the characteristics of the subjects within 1-2 hours rather than non-regular programs depending on subjects, patterns, and operating method (Son et al., 2012), and subdivide the subjects according to the diagnosis by training experts in the relevant fields (forest health, forest exercise, forest experience in medicine, healthcare, nursing) (Hong and Lee, 2018). In this study, cancer patients showed a strong intention to participate in forest healing programs, and they tended to prefer mornings on 
Table 5. Differences in preference for forest healing programs according to gender

\begin{tabular}{ccccccccc}
\hline & Spouse/lover & Children & Fiend & Alone & Etc. & Total & $\chi^{2}$ & $p$ \\
\hline Male & $36(81.8)$ & $2(4.5)$ & $2(4.5)$ & $3(6.8)$ & $1(2.3)$ & 44 & \multirow{2}{*}{12.47} & .014 \\
Female & $52(52.0)$ & $9(9.0)$ & $22(22.0)$ & $15(15.0)$ & $2(2.0)$ & 100 & & \\
\hline Total & 88 & 11 & 24 & 18 & 3 & $144(100)$ & & \\
\hline
\end{tabular}

Table 6. Differences in frequency of visits to mountains or forests according to cancer types

\begin{tabular}{ccccccc}
\hline Mountain, forest visit & Once a week & Once every 6 months & Less than once a year & Total & $\chi^{2}$ & $p$ \\
\hline Thyroid cancer & $1(7.1)$ & $9(64.3)$ & $4(28.6)$ & 14 & & \\
Colorectal cancer & $4(57.1)$ & $0(0)$ & $3(42.9)$ & 7 & & \\
Gastric cancer & $4(33.3)$ & $3(25.0)$ & $5(41.7)$ & 12 & \\
Breast cancer & $37(67.3)$ & $8(14.5)$ & $10(18.2)$ & 55 & 32.06 & .004 \\
Lung cancer & $5(41.7)$ & $3(25.0)$ & $4(33.3)$ & 12 & & \\
Liver cancer & $6(75.0)$ & $1(12.5)$ & $1(12.5)$ & 8 & \\
Ovarian cancer & $3(37.5)$ & $4(50.0)$ & $1(12.5)$ & 8 & \\
Various cancer & $15(62.5)$ & $5(20.8)$ & $4(16.7)$ & 24 & \\
Total & $75(53.6)$ & $33(23.6)$ & $32(22.9)$ & $141(100)$ & \\
\hline
\end{tabular}

Table 7. Differences in the perception of forest healing according to cancer types

\begin{tabular}{|c|c|c|c|c|c|}
\hline Forest healing awareness & Acquaintance & Do not know & Total & $\chi^{2}$ & $p$ \\
\hline Thyroid cancer & $14(100)$ & $0(0)$ & 14 & \multirow{9}{*}{18.01} & \multirow{9}{*}{.012} \\
\hline Colorectal cancer & $10(100)$ & $0(0)$ & 10 & & \\
\hline Gastric cancer & 10(90.9) & $1(9.1)$ & 11 & & \\
\hline Breast cancer & $50(90.9)$ & $5(9.1)$ & 55 & & \\
\hline Lung cancer & $7(58.3)$ & $5(41.7)$ & 12 & & \\
\hline Liver cancer & $7(87.5)$ & $1(12.5)$ & 8 & & \\
\hline Ovarian cancer & $6(100)$ & $0(0)$ & 6 & & \\
\hline Various cancer & $16(72.7)$ & $6(27.3)$ & 22 & & \\
\hline Total & $120(87.0)$ & $18(13.0)$ & $138(100)$ & & \\
\hline
\end{tabular}

Table 8. Differences in participating in forest healing according to cancer types

\begin{tabular}{|c|c|c|c|c|c|c|}
\hline Foreat healing program & Yes & Is average & Not rally & Total & $\chi^{2}$ & $p$ \\
\hline Thyroid cancer & $4(28.6)$ & 10(71.4) & $0(0)$ & 14 & \multirow{8}{*}{31.29} & \multirow{8}{*}{.005} \\
\hline Colorectal cancer & $5(50.0)$ & $5(50.0)$ & $0(0)$ & 10 & & \\
\hline Gastric cancer & $4(33.3)$ & $4(33.3)$ & $4(33.3)$ & 12 & & \\
\hline Breast cancer & $24(42.9)$ & $21(37.5)$ & 11(19.6) & 56 & & \\
\hline Lung cancer & $7(58.3)$ & $1(8.3)$ & $4(33.3)$ & 12 & & \\
\hline Liver cancer & $5(62.5)$ & $1(12.5)$ & $2(25.0)$ & 8 & & \\
\hline Ovarian cancer & $1(12.5)$ & $7(87.5)$ & $0(0)$ & 8 & & \\
\hline Various cancer & $15(62.5)$ & $5(20.8)$ & $4(16.7)$ & 24 & & \\
\hline Total & $65(45.1)$ & $54(37.5)$ & $25(17.4)$ & $144(100)$ & & \\
\hline
\end{tabular}


Table 9. Differences in the desired day of the week to participate in forest healing according to cancer types

\begin{tabular}{|c|c|c|c|c|c|c|c|c|c|c|}
\hline \multirow{2}{*}{ Day of participation } & \multicolumn{2}{|c|}{ Weekday } & \multicolumn{2}{|c|}{ Saturday } & \multicolumn{2}{|c|}{ Sunday } & \multirow{2}{*}{$\begin{array}{c}\text { Does not } \\
\text { matter }\end{array}$} & \multirow{2}{*}{ Total } & \multirow{2}{*}{$\chi^{2}$} & \multirow{2}{*}{$p$} \\
\hline & Morning & Afternoon & Morning & Afternoon & Morning & Afternoon & & & & \\
\hline Thyroid cancer & $7(50.0)$ & $1(7.1)$ & $3(21.4)$ & $0(0)$ & $2(14.3)$ & $0(0)$ & $1(7.1)$ & 14 & \multirow{8}{*}{59.68} & \multirow{8}{*}{.038} \\
\hline Colorectal cancer & $7(70.0)$ & $0(0)$ & $2(20.0)$ & $0(0)$ & $0(0)$ & $0(0)$ & $1(10.0)$ & 10 & & \\
\hline Gastric cancer & $5(41.7)$ & $1(8.3)$ & $3(25.0)$ & $0(0)$ & $0(0)$ & $0(0)$ & $3(25.0)$ & 12 & & \\
\hline Breast cancer & $21(37.5)$ & $7(12.5)$ & $9(16.1)$ & $5(8.9)$ & $4(7.1)$ & $2(3.6)$ & $8(14.3)$ & 56 & & \\
\hline Lung cancer & $2(16.7)$ & $6(50.0)$ & $2(16.7)$ & $0(0)$ & $1(8.3)$ & $0(0)$ & $1(8.3)$ & 12 & & \\
\hline Liver cancer & $8(100)$ & $0(0)$ & $0(0)$ & $0(0)$ & $0(0)$ & $0(0)$ & $0(0)$ & 8 & & \\
\hline Ovarian cancer & $4(50.0)$ & $0(0)$ & $1(12.5)$ & $0(0)$ & $0(0)$ & $0(0)$ & $3(37.5)$ & 8 & & \\
\hline Various cancer & $17(70.8)$ & $0(0)$ & $2(8.3)$ & $0(0)$ & $1(4.2)$ & $1(4.2)$ & $3(12.5)$ & 24 & & \\
\hline Total & $71(49.3)$ & $15(10.4)$ & $22(15.3)$ & $5(3.5 \%)$ & $8(5.6 \%)$ & $3(2.1 \%)$ & $20(13.9)$ & $144(100)$ & & \\
\hline
\end{tabular}

Table 10. Differences in the desired time for participating in forest healing according to cancer types

\begin{tabular}{|c|c|c|c|c|c|c|c|}
\hline Engagement time & Dawn & Morning & Afternoon & Does not matter & Total & $\chi^{2}$ & $p$ \\
\hline Thyroid cancer & $0(0)$ & $12(85.7)$ & $0(0)$ & $2(14.3)$ & 14 & \multirow{8}{*}{49.36} & \multirow{8}{*}{.000} \\
\hline Colorectal cancer & $0(0)$ & $9(90.0)$ & $1(10.0)$ & $0(0)$ & 10 & & \\
\hline Gastric cancer & $1(8.3)$ & $9(75.0)$ & $0(0)$ & $2(16.7)$ & 12 & & \\
\hline Breast cancer & $1(1.8)$ & $41(73.2)$ & $9(16.1)$ & $5(8.9)$ & 56 & & \\
\hline Lung cancer & $0(0)$ & $6(50.0)$ & $6(50.0)$ & $0(0)$ & 12 & & \\
\hline Lliver cancer & $2(25.0)$ & $6(75.0)$ & $0(0)$ & $0(0)$ & 8 & & \\
\hline Ovarian cancer & $0(0)$ & $8(100)$ & $0(0)$ & $0(0)$ & 8 & & \\
\hline Various cancer & $0(0)$ & $18(75.0)$ & $1(4.2)$ & $5(20.8)$ & 24 & & \\
\hline Total & $4(100)$ & $109(100)$ & $17(100)$ & $14(100)$ & $144(100)$ & & \\
\hline
\end{tabular}

weekdays. In further research, it is necessary to reclassify the patients by type of cancer and analyze their interest, preference, and needs to develop and implement scientific, systematic, sustainable, and regular forest healing programs based on the interest and healing factors, thereby ultimately improving the quality of the forest healing programs for cancer patients.

\section{Preference in forest healing program}

The forest healing program most preferred by cancer patients was kinesiology $(M=4.39)$, followed by climate/water therapy $(M=4.11)$, diet therapy $(M=3.78)$, psychotherapy $(\mathrm{M}=3.76)$, and plant therapy $(\mathrm{M}=3.45)$. The most preferred activity in kinesiology was walking through the forest $(M=4.47)$, forest exercises $(M=4.35)$, and laughter exercises $(M=4.22)$. In climate therapy, it was forest bathing $(\mathrm{M}=4.38)$, followed by natural meditation $(\mathrm{M}=4.26)$ and wind bathing $(M=4.22)$. In water therapy, the most preferred activity was anion bathing $(\mathrm{M}=4.02)$ and water sound listening and meditation $(\mathrm{M}=3.85)$. In diet therapy, the subjects most preferred drinking tea $(\mathrm{M}=4.32)$ and cooking with plants. In psychotherapy, the most preferred activity was abdominal breathing $(\mathrm{M}=4.23)$, followed by lymphatic massage $(M=4.13)$, and body scan $(M=3.75)$ (Table 11). Activities in forest healing are classified by movement (static-dynamic), place (indoors-outdoors), five senses, therapy (plant, kinesiology, climate, psychotherapy, diet, water), and subject (general, chronic, environmental, toxic), but to actually apply them, it is necessary to develop programs depending on the diagnosis (Kim et al., 2019). Healing factors are classified into physical (water, sunlight, topography), chemical (phytoncide, anionic oxygen), sensory (sound, fragrance, taste, touch), and sociopsychological factors, and physical, physiological, sensory, and mental communion through forest healing factors promote physical 
Table 11. Forest healing program preference

\begin{tabular}{|c|c|c|c|}
\hline Program & Mean & $\mathrm{SD}$ & Min \\
\hline Psychotherapy & 3.76 & .76 & 1.00 \\
\hline Double breathing & 4.23 & 1.02 & 1.00 \\
\hline Lymph massage & 4.13 & 1.22 & 1.00 \\
\hline Body scan & 3.75 & 1.11 & 1.00 \\
\hline Sharing empathy & 3.56 & 1.09 & 1.00 \\
\hline Recall therapy & 3.11 & 1.20 & 1.00 \\
\hline Kinesiology & 4.39 & .66 & 2.00 \\
\hline Forest, mountain walk & 4.47 & .82 & 1.00 \\
\hline Forest gymnastics & 4.35 & .88 & 1.00 \\
\hline Laughter movement & 4.22 & .91 & 1.00 \\
\hline Band exercise & 3.39 & 1.08 & 1.00 \\
\hline Music rhythmic gymnastics & 3.78 & 1.07 & 1.00 \\
\hline Nordic walking & 3.18 & 1.18 & 1.00 \\
\hline Climate therapy & 4.11 & .77 & 1.00 \\
\hline Forest bathing & 4.38 & 1.00 & 1.00 \\
\hline Natural meditation & 4.26 & .94 & 1.00 \\
\hline Wind bath & 4.22 & 1.05 & 1.00 \\
\hline Aromatherapy & 4.03 & 1.04 & 1.00 \\
\hline Nap & 3.65 & 1.14 & 1.00 \\
\hline Plant therapy & 3.45 & .86 & 1.14 \\
\hline Landscape view & 3.99 & 1.08 & 1.00 \\
\hline Forest horticulture treatment & 3.88 & 1.12 & 1.00 \\
\hline Plant observation & 3.56 & 1.19 & 1.00 \\
\hline Gardening & 3.50 & 1.21 & 1.00 \\
\hline Making natural objects & 3.15 & 1.09 & 1.00 \\
\hline Dyeing natural products & 3.09 & 1.17 & 1.00 \\
\hline Listen to the plant lecture & 2.94 & 1.31 & 1.00 \\
\hline Water therapy & 4.11 & .85 & 1.67 \\
\hline Anion bath & 4.02 & 1.13 & 1.00 \\
\hline Water meditation/the sound & 3.85 & 1.17 & 1.00 \\
\hline Water cannon/water play & 2.81 & 1.21 & 1.00 \\
\hline Diet therapy & 3.78 & .93 & 1.00 \\
\hline Drinking tea & 4.32 & .83 & 1.00 \\
\hline Plant cooking & 3.70 & 1.24 & 1.00 \\
\hline Food therapy & 3.33 & 1.28 & 1.00 \\
\hline
\end{tabular}

and mental health (Kim et al., 2008). Activities that men and women most preferred in urban forests were forest bathing, wind bathing, and sunbathing, as well as looking at the natural landscape (Park and Koo, 2018). In this study, by developing and implementing a forest healing program that is suitable for the disease and characteristics of cancer
Table 12. Differnces in preference for forest healing programs according to gender

\begin{tabular}{ccccc}
\hline Variable & Group & $\mathrm{n}$ & $\mathrm{M}$ & $t(p)$ \\
\hline \multirow{2}{*}{ Diet therapy } & Male & 44 & 3.45 & $-2.96^{* *}$ \\
& Female & 100 & 3.93 & $(.004)$ \\
\hline **
\end{tabular}

${ }^{* *} p<.01$.

patients using forest healing factors of kinesiology, climate therapy, water therapy, psychotherapy, and plant therapy preferred by cancer patients, it would be possible to provide effective programs for cancer patients with a high level of satisfaction.

\section{Difference of preference in forest healing depending on gender and cancer types}

As a result of conducting an independent samples t-test to verify the difference of preference in forest healing program by gender, it was found that there was a significant difference in diet therapy by gender $(t=-2.96, p<.01)$. Women more preferred diet therapy than men, whereas there was no significant difference in psychotherapy, kinesiology, climate therapy, plant therapy, and water therapy (Table 12). There was also no significant difference of preference in forest healing program by cancer types. The healthy group of subjects preferred a sensitive approach using five senses depending on their stress level, whereas the risk group required help from specialists with a cognitive (lecture, counseling, coaching) approach (Kim, 2016a). In urban forests, participants preferred forest bathing, wind bathing, meditating, listening to the water, and foot bathing. Their biggest purpose of participation was to refresh themselves, relax, and promote health. Most men and women most preferred forest healing factors and attached great importance to forest healing programs and instructors (Park and Koo, 2018). In this study, female respondents preferred diet therapy. In further research, it is necessary to accurately determine the preferences of male and female cancer patients and scientifically develop and implement forest healing programs for each therapy based on advice from specialists (forest health, forest exercise, forest experience in medicine, healthcare, nursing), depending on the characteristics of the subjects. 


\section{Preference in the purpose of forest healing programs}

For the purpose of participating in forest healing programs, the subjects most preferred the psychological $(\mathrm{M}=$ 4.26) domain, followed by physical $(\mathrm{M}=3.76)$, social $(\mathrm{M}=$ 3.68), and cognitive $(M=3.64)$ domains. They had high expectations for relieving anxiety and depression through forest healing programs in the psychological aspect, relieving pain in the physical aspect, improving leisure in the social aspect, and improving concentration and sensory perception ability in the cognitive aspect, but there was no significant difference of preference in the purpose of forest healing programs by gender and cancer types (Table 13). To promote mental healing through social, psychological, and physical adaptability using plants, it is necessary to subdivide the aspects into emotional, social, cognitive, and physical domains depending on the subjects, purpose, and place, which are promoted by interactions (Relf, 1998). Depending on the stress level, the healthy group preferred walking in the forest, listening to the water, and experiencing the five senses, whereas the high-risk stress group pre-

Table 13. Preference for forest healing programs

\begin{tabular}{|c|c|c|c|}
\hline Program & Mean & SD & Min. \\
\hline Physical domain & 3.76 & .94 & 1.00 \\
\hline Body function & 4.19 & 1.05 & 1.00 \\
\hline Pain relief & 3.94 & 1.17 & 1.00 \\
\hline Relieve gastrointestinal symptoms & 3.64 & 1.25 & 1.00 \\
\hline Relieve vomiting symptoms & 3.26 & 1.19 & 1.00 \\
\hline Psychological domain & 4.26 & .79 & 1.00 \\
\hline Depression & 4.43 & .88 & 1.00 \\
\hline Relief of anxiety & 4.29 & 1.00 & 1.00 \\
\hline Improve emotion control & 4.17 & .95 & 1.00 \\
\hline Improved self-esteem & 4.15 & 1.00 & 1.00 \\
\hline Social domain & 3.68 & .75 & 1.00 \\
\hline Improve leisure & 4.15 & .87 & 1.00 \\
\hline Improve interpersonal skills & 3.81 & 1.01 & 1.00 \\
\hline Improve communication skills & 3.74 & .99 & 1.00 \\
\hline Job skills improvement & 3.04 & 1.07 & 1.00 \\
\hline Cognitive domain & 3.64 & .89 & 1.00 \\
\hline Improve concentration & 3.96 & 1.02 & 1.00 \\
\hline Sensory perception & 3.65 & 1.08 & 1.00 \\
\hline Improve problem solving & 3.51 & 1.04 & 1.00 \\
\hline Improve your vocabulary & 3.44 & 1.09 & 1.00 \\
\hline
\end{tabular}

ferred cognitive programs such as lectures, counseling, and coaching (Kim, 2016a). Among factors that affect psychosocial adaptation of cancer patients, stress has a direct effect; thus, not only the process of curing cancer but also psychosocial adaptation to coping with the process is important (Oh and Jang, 2014). To increase the therapeutic effects for cancer patients, it is necessary to first develop forest healing programs that meet the purpose of the treatment by reflecting the specificity of cancer types. Cancer patients need forest healing programs that can promote both their psychological stability and physical health, which requires systematic and scientific verification and analysis on the cancer types that the subjects are diagnosed with as well as the symptoms.

\section{Conclusion}

This study was conducted to develop and implement differentiated forest healing programs by analyzing the preferences and needs of cancer patients and increase the effects of the programs. Thus, we conducted a self-administered survey from October 2018 to April 2019 on the subjects diagnosed with cancer. The sample size $(n=144)$ was the appropriate size required by G-Power, and the retrieved responses were analyzed using SPSS 25.0. 87\% (120 subjects) were aware of forest healing programs, most of them from TV, followed by the internet and SNS. 79.2\% (114 subjects) did not have experience participating in a forest healing program, but $82.6 \%$ (118 subjects) had intention to participate. This indicates that even though not many of them have experience participating in forest healing, they showed high interest and needs for participation. They preferred to participate in spring $(29.9 \%)$ and fall $(27.8 \%)$, in programs carried out for 1.5-2 hours in the morning on weekdays, which suggests the need to develop various programs using forests in the four seasons. In the needs for forest healing programs, the subjects most preferred kinesiology, followed by climate therapy and water therapy, then diet therapy, psychotherapy, and plant therapy. Exercise programs for cancer patients will help lower their depression and increase resilience through engagement in nature as well as various physical and emotional activities. Moreover, 
subjective, direct activities in the physical environment of a forest will have positive effects on improving the physiological functions and lifting the mood. For the purpose of participation, the subjects most preferred the psychological domain, followed by physical, social, and cognitive domains. This indicates that, although this study is limited as it is conducted on 144 cancer patients without enough male respondents, surveying the needs and purposes of cancer patients is significant in that it has raised the need for continuous research on development and implementation of forest healing programs. Furthermore, developing manuals from implementation of forest healing programs is an inevitable task to improve the effects of forest healing. This study failed to classify many cancer types for statistics as it was difficult to obtain a greater sample size due to the nature of the subjects, and thus it is necessary to conduct a more systematic survey by classifying the diagnosis. Further research must provide ways to plan, develop, and implement differentiated forest healing programs considering the psychological and physical characteristics of cancer patients as well as the natural environment. It is first necessary to develop forest healing programs that meet the therapeutic purposes based on surveys on the needs and purposes of the programs according to the classification of diagnosis for the five main types of cancer (gastric cancer, colorectal cancer, liver cancer, breast cancer, cervical cancer) in the national cancer policy. There is also a need to plan forest healing program that can promote both psychological stability and physical health of cancer patients and verify and evaluate their effects based on specialized training of forest healing instructors.

\section{References}

Baik, H.W and M. Kim. 2014. The relation between comprehensive health needs of cancer patient and the quality of life. J. Digit. Converg. 12(12):447-482. https://doi.org /10.14400/JDC.2014.12.12.477

Choi Y.H and Y.S. Ha. 2014. The effectiveness of a forest-experience-integration intervention for community dwelling cancer patients depression and resilience. J. Korean Acad. Community Health Nurs. 25(2):109-118. http://dx.doi.org/10.12799/jkachn.2014.25.2.109

Hong, M.A., H.G. Lee., E. Han, and Y.K. Kwon. 2010. A States about forest therapy program in korean and the prospect for the fusion of Korean medicine with forestry. Korea J. Orient. Med. 16(3):95-105.

Hong, J.Y and J.H. Lee. 2018. Analysis on activities of forest healing program in healing forests. J. Korean Inst. For. Recreat. 22(4):1-9. https://doi.org/10.34272/forest.2 018.22.4.001

Kaplan, S. 1995. The restorative benefits of nature : Toward an integrative framework. J. Environ. Psychol. 15(3): 169-182.

Lee, E.D., S.J. Park., R.H. Yoo and S.J. Hong. 2011. Analysis on visitors of recreation forest in and around the metropolitan area. J. Korean Inst. For. Recreat. 15(2): 101-109. https://www.kci.go.kr/kciportal/ci/sereArticleS earch/ciSereArtiView.kci?sereArticleSearchBean.artiId $=$ ART001576197

Kim, G.Y., S.S. Choi., S.M. Park., H.K. Hur, and H.Y. Song. 2002. Development of needs assessment instrument for the patients with cancer. Korean J. Hosp. Palliat. Care 5(2):136-145.

Kim, K.W. 2006. Theoretical study of characteristics of therapeutic elements and application to forest therapy. J. Korean Soc. People Plants Environ. 9(4):111-123.

Kim, K.W., Y.H. Lee., H.Y. Kim., C.Y. Kim., J.W. Kim, and L.H. Yoo. 2008. Management of forest healing program in Saneum forest (abstr.). J. Korean Inst. For. Recreat. 4:41-44.

Kim, Y.H., D.J. Kim., P.S. Yeoun, and B.J. Choi. 2014a. Preference analysis of general adult on the forest and forest road for the development of forest therapy program. Korean J. Environ. Ecol. 28(5):597-606. http://dx.doi.org/10.13047/KJEE.2014.28.5.597

Kim, Y.H., D.J. Kim., P.S. Yeoun, and B.J. Choi. 2014b. The analysis of interests and needs for the development of forest therapy program in adults. J. Korean Inst. For. Recreat. 18(3): 45-59. https://doi.org/10.34272/forest.20 14.18.3.005

Kim, Y.G., S.H. Lee, Y.H. Kim, J.O. Eum, Y.R. Yim, T.G. Ha, and C.S. Shin. 2015. The influence of forest activity intervention on anxiety, depression, profile of mood states(POMS) and hope of cancer patients. J. Korean Inst. For. Recreat. 19(1):65-74. https://doi.org/10.34272/ 
forest.2015.19.1.007

Kim, Y.H., D.I. Kim., E.J. Kim., P.S. Yeoun., B.J. Choi., J.K. Kim, and Y.S. Kim. 2015a The preference analysis of forest therapy program with regard to MBTI personality types. Korean J. Environ. Ecol. 29(3):485-498. http://dx.doi.org/10.13047/KJEE.2015.29.3.485

Kim, Y.H., E.J. Lee., D.J. Kim., P.S. Yeoun, and B.J. Choi. 2015b. The preference analysis of adults on the forest therapy program with regard to demographic characteristics. J. Korean For. Soc. 104(1):150-161. http://dx.doi. org/10.14578/jkfs.2015.104.1.150

Kim, Y.H. 2016a. Preference analysis of forest therapy program according to the stress level. Korean J. Environ. Ecol. 30(3):432-442. http://dx.doi.org/10.13047/KJEE.2 016.30 .3 .434

Kim, Y.H. 2016b. The analysis of program preferences for the development of forest therapy program. Korean J. Environ. Ecol. 30(1):118-129. http://dx.doi.org/10.1304 7/KJEE.2016.30.1.118

Kim, Y.H. 2016c. The analysis of needs regarding forest visit frequency for the development of forest therapy program. J. Korean Soc. People Plants Environ. 19(2): 129-137. https://doi.org/10.11628/ksppe.2016.19.2.129

Kim, Y.H., D.W. Joung, and B.J. Park. 2019. A study on analyze contents of forest based therapeutic programs in Korea. J. Korean Inst. For. Recreat. 23(1):43-58. https://doi.org/10.34272/forest.2019.23.1.005

Korea Forest Service. 2011. Forest health. Retrieved from http://www.forest.go.kr

Lee, J.H., R.H. Hee, and J.W. Lee. 2016. Analysis on visitors of healing forest for improvement of forest healing program. J. Korean Inst. For. Recreat. 20(4):73-80. https://doi.org/10.34272/forest.2016.20.4.007

Lee, Y.H. and K.W. Kim. 2011. Visitors' behavior and needs of national recreational forests in Korea. J. Korean Soc. People Plants Environ. 14(4):245-252.

National Cancer Information Center. 2019. Cancer in statistics. Retrieved from http://www.cancer.go.kr

Oh, B.J. and E.S. Jang. 2014. Effects of psychosocial interventions on cortisol and immune parameters in patient with cancer: A meta-analysis. J. Korean Acad. Nurs. 44(4):446-457. http://dx.doi.org/10.4040/jkan.2014.44.4.446

Park, B.J. 2010. Experimental approach of therapeutic effect of forest recreation activities: Focused on viewing and walking in forest environments. Doctoral dissertation, Chungnam National University, Daejeon, Korea.

Park, S.H. and C.D. Koo. 2018. Needs analysis for the development of forest therapy program utilizing the urban forest: Focused on the visitors of Incheon grand park. J. Korean Inst. For. Recreat. 22(4):49-58. https://doi.org/ 10.34272/forest.2018.22.1.002

Relf. P.D. 1998. The role of horticulture in human well-bing and quality of life. J. Korean Soc. Plants People Environ. 1(1):12-21.

Shin, W.S., P.S. Yeoun., J.H. Lee., S.K. Kim, and J.S. Joo. 2007. The Relationships among forest experience, anxiety and depression. J. Korean Inst. For. Recreat. 11(1): 27-32.

Son, J.W., S.Y. Ha, and J.J. Kim. 2012. A study on visitor characteristics for trail program development. J. Korean For. Soc. 101(3):469-479.

Yeom, D.G., D.W. Joung, G.W. Kim, and B.J. Park. 2015. A strudy of an expert opinion survery for designing a forest healing program. J. Korean Inst. For. Recreat. 19(2):1-12. https://doi.org/10.34272/forest.2015.19.2.001 